\title{
Carbapenem-resistant Pseudomonas aeruginosa originating from farm animals and people in Egypt
}

\author{
Esraa A. Elshafiee ${ }^{1}$, Sara M. Nader ${ }^{1}$, Sohad M. Dorgham², Dalia A. Hamza ${ }^{1}$ \\ ${ }^{1}$ Department of Zoonoses, Faculty of Veterinary Medicine, Cairo University, 12211, Cairo, Egypt \\ ${ }^{2}$ Department of Microbiology and Immunology, National Research Centre, 12211, Cairo, Egypt \\ daliahamza@cu.edu.eg
}

Received: February 7, $2019 \quad$ Accepted: July 24, 2019

\begin{abstract}
Introduction: Carbapenem-resistant Pseudomonas aeruginosa (CRPA) has become the leading cause of health careassociated infections. Treatment is difficult due to the lack of an effective antimicrobial therapy, and mortality is high. This study investigated the occurrence of CRPA in farm animals (buffaloes and cattle), livestock drinking water, and humans in Egypt. Material and Methods: A total of 180 samples were examined: 50 faecal each from buffaloes and cattle, 30 of livestock drinking water, and 50 stool from humans. The samples were cultured on cetrimide agar and the plates were incubated aerobically at $37^{\circ} \mathrm{C}$ for $24 \mathrm{~h}$. The isolates were examined for the presence of the bla $a_{K C}$, bla $a_{O A-48}$, and bla $a_{N D M}$ carbapenemase-encoding genes using PCR and investigated for the exotoxin A $($ tox $A)$ gene. The tox $A$ gene from carbapenem-group resistant isolates was phylogenetically analysed. Results: $P$. aeruginosa was isolated from buffaloes, cattle, drinking water, and humans, with occurrences of $40 \%, 34 \%$, $10 \%$, and $20 \%$, respectively. Carbapenem resistance genes were found in $60 \%, 59 \%, 67 \%$, and $70 \%$ in buffalo, cattle, water and human samples, respectively. The toxA gene was detected in $80 \%$ of samples. The phylogenetic analysis showed that cattle and water sequences were in one cluster and more related to each other than to human isolates. Conclusion: Occurrence of CRPA among farm animals, drinking water, and humans was high, reflecting the environmental origin of $P$. aeruginosa and highlighting contaminated water as a potential transmitter of CRPA to livestock and next to humans.
\end{abstract}

Keywords: farm animals, humans, water, antibiotic-resistant Pseudomonas aeruginosa, carbapenem, Egypt.

\section{Introduction}

Pseudomonas aeruginosa is Gram-negative bacterium which exhibits a wide distribution range in nature and colonises diverse ecological niches in both soil and water. The host range of $P$. aeruginosa is very broad, spanning aquatic and terrestrial plants, animals, and humans (25). P. aeruginosa is an opportunistic human pathogen and can pose serious health risks to elderly and immunocompromised individuals. Aquatic reservoirs of $P$. aeruginosa are rivers (22), open oceans (12), recreational waters (2), and wastewater (15), making these bacteria a growing public health concern (24). Several factors, including biofilm formation, contribute to the survival of $P$. aeruginosa in a variety of environmental conditions $(13,23)$ and aid bacterial proliferation and distribution. $P$. aeruginosa, like many other pseudomonads, harbours intrinsic resistance to many classes of drugs, and to make matters worse, the bacteria can expand their antibiotic resistance by mutations or by acquiring resistance through horizontal gene transfer, causing therapeutic failures in humans (6). On the other hand, the dissemination of these drugresistant bacteria from hospitals to the natural environment may increase the occurrence of community-acquired infections. In fact, although the source has yet to be clearly established, wastewater treatment plants have been found to harbour antibioticresistant $P$. aeruginosa strains in their effluent and in the surface water downstream (21).

Carbapenems have recently begun to be utilised for treatment of serious $P$. aeruginosa infections. They are regarded as the last-line treatment against multidrugresistant (MDR) Gram-negative bacterial diseases (16). Carbapenem resistance in $P$. aeruginosa is particularly troublesome because this class of $\beta$-lactams represents the last therapeutic resource for the control of bacterial infections. Authorisation for use in veterinary pharmaceuticals around the world (27) has not been given to carbapenems. In fact, the precise origins of carbapenemase genes in animals remain undefined, and this indicates that these genes may have been mobilised 
from environmental bacteria into animals due to the close contact animals have with the environment.

Since the carbapenemases in $P$. aeruginosa from non-human sources are not yet being systematically investigated, the objective of this study was to examine carbapenem-resistant $P$. aeruginosa in livestock animals and water and its implication for human health.

\section{Material and Methods}

Study samples. A total of 180 samples were examined. Samples of faeces totalling 100 were collected using sterile swabs from apparently healthy animals ( 50 buffaloes and 50 cattle) on three farms in the Giza Governorate. Thirty samples of livestock drinking water $(1 \mathrm{~L}$ each) were collected from the same farms. Water samples were collected in sterile glass bottles containing sodium thiosulphate as a dechlorinating agent. In addition, 50 human faecal samples were also collected from people working on these farms. All samples were stored on ice and immediately sent to the laboratory for further testing.

Isolation and identification of Pseudomonas aeruginosa

Faecal samples. Faecal samples from animals and humans were cultured on cetrimide agar aerobically at $37^{\circ} \mathrm{C}$ for $24 \mathrm{~h}$.

Water samples. Bacteria were trapped by filtration of $1 \mathrm{~L}$ of water through $0.45 \mu \mathrm{m}$ sterile nitrocellulose filters (Sartorius, Germany). The filters were then vortexed in peptone broth and bacteria were allowed to grow in this broth at $37^{\circ} \mathrm{C}$ for $20 \mathrm{~h}$ according to Hikal et al. (11), then they were transferred to cetrimide agar plates and incubated aerobically at $37^{\circ} \mathrm{C}$ for $24 \mathrm{~h}$.

The suspected colonies from faecal and water samples were identified according to Quinn et al. (20), and the pure isolates of $P$. aeruginosa were confirmed using API 20NE identification kit (bioMérieux, France).

Antibiotic susceptibility test. The standard disc diffusion method (Kirby-Bauer) on Mueller-Hinton agar plates) was performed for the antibiotic susceptibility test according to Clinical and Laboratory Standards Institute guidelines (7). P. aeruginosa isolates were tested using three carbapenem derivatives: imipenem, meropenem, and ertapenem.

Genomic DNA extraction. All $P$. aeruginosa isolates were extracted using a DNA Mini Kit (Qiagen, Germany) according to the manufacturer's protocol.
PCR amplification of the resistant genes. All isolates were examined for the carbapenemase-encoding genes bla $a_{K P C}, b l a_{O X A-48}$, and bla $_{N D M}$ (9). These gene fragments were amplified using the gene-specific PCR primers listed in Table 1. PCR mixtures consisted of $1 \mu \mathrm{L}$ of genomic DNA template, $12.5 \mu \mathrm{L}$ of DNA polymerase master mix (Takara Bio Inc., Japan), and $0.4 \mu \mathrm{M}$ of each primer, for a total reaction volume of $25 \mu \mathrm{L}$. PCR amplifications of the bla $a_{K P C}, b a_{O X A-48}$, and $b l a_{N D M}$ fragments were carried out with the following cycling parameters: 30 cycles with a 1-min denaturation step at $94^{\circ} \mathrm{C}$, a 1 -min annealing step at $55^{\circ} \mathrm{C}$, and a $2-\mathrm{min}$ extension step at $72^{\circ} \mathrm{C}$, and a final single 10 -min extension step at $72^{\circ} \mathrm{C}$.

PCR amplification of the toxin gene. All $P$. aeruginosa isolates were examined for tox $A$ gene (28). The gene-specific primers are listed in Table 1.

PCR mixtures consisted of $3 \mu \mathrm{L}$ of genomic DNA template, $25 \mu \mathrm{L}$ of DNA polymerase master mix (Takara Bio Inc., Japan), and $0.4 \mu \mathrm{M}$ of each primer, for a total reaction volume of $50 \mu \mathrm{L}$. The cycling parameters for the tox $A$ PCR were as follows: 30 cycles with a 1-min denaturation step at $94^{\circ} \mathrm{C}$, a 1 -min annealing step at $68^{\circ} \mathrm{C}$, and a 1 -min extension step at $72^{\circ} \mathrm{C}$, and a final single 7-min extension step at $72^{\circ} \mathrm{C}$.

PCR product in a $5 \mu \mathrm{L}$ volume was electrophoresed on $1.5 \%$ agarose gel to determine the size of the product.

Sequence analysis of tox $\boldsymbol{A}$ gene. After selecting one isolate each from animal, water, and human samples that showed resistance to carbepenem genes, the amplified toxA fragments were purified using the QIAquick gel extraction kit (Qiagen, Germany) according to the manufacturer's instructions and sequenced at Promega Lab Technology (Germany) by using the forward and reverse primers of tox $A$ listed in Table 1. The sequences of the tox $A$ gene were deposited in the National Center for Biotechnology Information (NCBI) GenBank database under the accession numbers KY407567, KY407566, and KY454872 from animal, water, and human, respectively.

The three toxA genes sequenced in this study were compared with the sequences available in the public domain using the NCBI BLAST server. Publicly available tox $A$ gene sequences were downloaded from the NCBI GenBank and aligned using ClustalW in BioEdit version 7.0.1.4. Phylogenetic analysis was performed with MEGA version 7, using the neighbourjoining approach. The bootstrap consensus tree was inferred from 950 replicates (Fig. 1).

Table 1. List of primers used in this study

\begin{tabular}{|c|c|c|c|}
\hline Gene & Sequence $\left(5^{\prime}-3^{\prime}\right)$ & Size (bp) & References \\
\hline \multirow[t]{2}{*}{$b l a_{K P C}$} & F: ATGTCACTGTATCGCCGTCT & \multirow[t]{2}{*}{882} & \multirow{6}{*}{ Hamza et al. (9). } \\
\hline & R: TTTTCAGAGCCT TACTGCCC & & \\
\hline \multirow[t]{2}{*}{ bla $_{O X A-48}$} & F: TTGGTGGCATCGATTATCGG & \multirow[t]{2}{*}{743} & \\
\hline & R: GAGCACTTCTTTTGTGATGGC & & \\
\hline \multirow{2}{*}{$b l a_{N D M}$} & F: GGTTTGGCGATCTGGTTTTC & \multirow[t]{2}{*}{621} & \\
\hline & R: CGGAATGGCTCATCACGATC & & \\
\hline \multirow[t]{2}{*}{ tox $A$} & F: GACAACGCCCTCAGCATCACCAGC & \multirow[t]{2}{*}{396} & \multirow{2}{*}{ Xu et al. (28). } \\
\hline & R: CGCTGGCCCATTCGCTCCAGCGCT & & \\
\hline
\end{tabular}




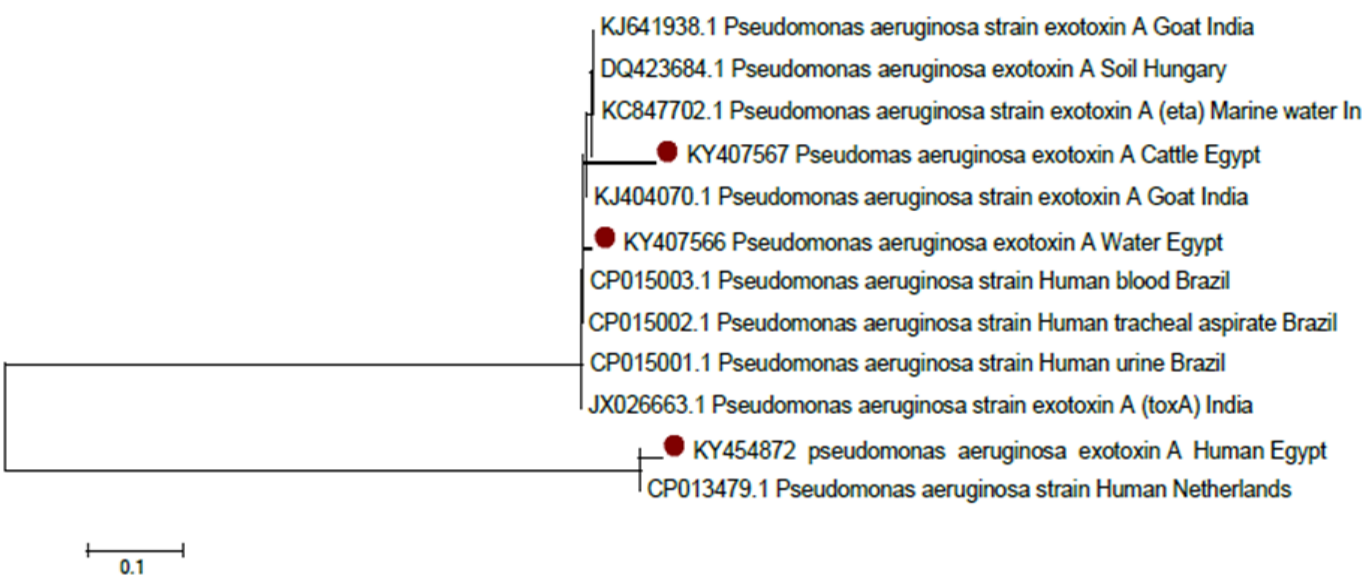

Fig. 1. Phylogenetic analysis of the toxA gene. The toxA genes sequenced in this study are marked with red solid dots. All other sequences are derived from the NCBI GenBank database

Table 2. Occurrence among different sources of $P$. aeruginosa, carbapenem-resistant $P$. aeruginosa (CRPA), and exotoxin A in the tested samples

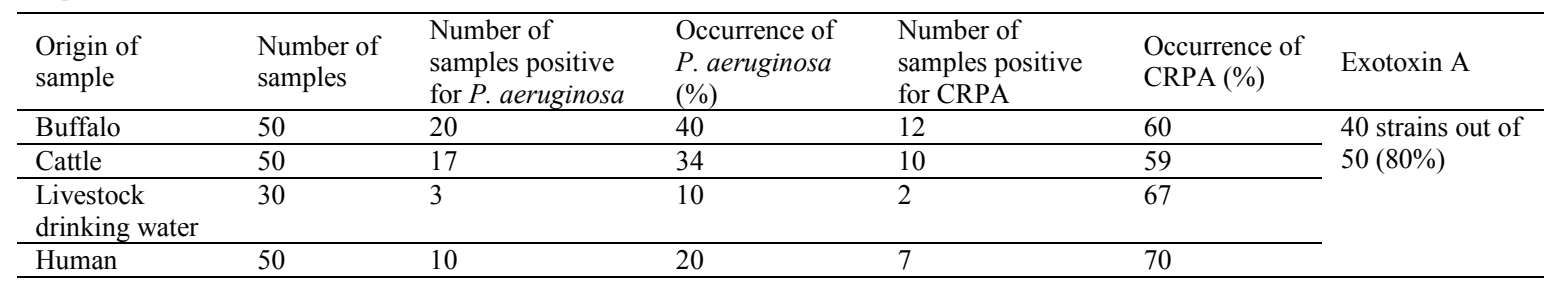

\section{Results}

Samples from buffaloes, cattle, livestock drinking water, and humans were examined for the presence of $P$. aeruginosa. The incidence of $P$. aeruginosa in faecal samples of buffaloes was $40 \%$ (20 out of 50 samples) whereas $34 \%$ of samples from cattle (17 out of 50 samples) were positive for this bacterium. Its incidence in drinking water was $10 \%$ (3 out of 30 samples). In human stool samples, the occurrence was 20\% (10 out of 50 samples). Therefore, out of 180 samples collected, we identified 50 isolates of $P$. aeruginosa (Table 2).

All $P$. aeruginosa isolates were subjected to an antibiotic disc diffusion assay with carbapenem-group antibiotics (Table 2). We further characterised these isolates for the presence of the $\beta$-lactam resistance genes $b l_{K P C}, b_{a_{O X A-48}}$, and $b l a_{N D M}$, and the virulence of the toxA gene (Table 2). We found that $60 \%$ and $59 \%$ of animal isolates (buffalo and cattle), $67 \%$ of drinking water isolates, and $70 \%$ of human isolates were carbepenem resistant by both the disc diffusion method and testing for resistant genes. Furthermore, we found that 40 out of 50 isolates ( $80 \%$ prevalence) were positive for tox $A$ as they showed amplification of a $396 \mathrm{bp}$ tox $A$ specific fragment. Sequence analysis of the tox $A$ gene from isolates derived from cattle, water, and humans fell in two clusters, with sequences from cattle isolates (KY407567) and water isolates (KY407566) being more related to each other than to the sequence from bacteria isolated from human samples (KY454872).

\section{Discussion}

The present study was undertaken to examine the prevalence and origin of $P$. aeruginosa in farm animals, livestock drinking water, and humans in Egypt. A large number of investigations have been carried out on $P$. aeruginosa isolated from human infections while fewer are available on strains isolated from animals. In veterinary medicine, $P$. aeruginosa may be responsible for difficult-to-treat infections (8). The bacterium was detected in enzootic or epizootic flare-ups of mastitis in bovine species (18). In the present study, $P$. aeruginosa isolates were found in $40 \%$ and $34 \%$ of faecal samples of buffaloes and cattle, indicating the dissemination of $P$. aeruginosa in farm animals.

The occurrence of $P$. aeruginosa in the surface water used for drinking by the livestock was $10 \%$. It is apt to note that the cells of $P$. aeruginosa are able to proliferate in different environmental conditions or survive in a "viable but nonculturable state" (19). This observation can partially explain the low recovery of $P$. aeruginosa from water.

The use of antimicrobials in farming and livestock management has contributed to the spread of antibiotic resistance genes in the environment (14). Carbapenems are not licensed for use in veterinary medicine or livestock production anywhere around the world (27). However, in this study CRPA was recovered from $60 \%$ and $58 \%$ of animal isolates, $66 \%$ of water isolates, and $70 \%$ of human isolates. Screening for carbapenemaseencoding genes (bla K $_{K C}$, bla $a_{O X-48}$, and bla $_{N D M}$ ) by PCR showed that all phenotypically CRPA isolates harboured 
three resistant genes. The presence of such resistant genes in non-human sources including animals and water indicates that these carbapenemase genes may originate from environmental bacteria and mobilise into animals due to the close contact between the two. Another scenario was highlighted by Walsh et al. (26), who reported that chromosomal carbapenemase is naturally co-transcribed with other chromosomally located $\beta$-lactamases; moreover, the over-expression of such genes is induced by the administration of $\beta$-lactam or carbapenem antibiotics. Hence, the use of penicillins or penicillin- $\beta$-lactamase inhibitor combinations in veterinary medicine can create selective pressure for naturally occurring chromosomal carbapenemases, which, in theory, can eventually be mobilised. These findings are of great concern because carbapenemases in bacteria from non-human sources are not yet being systematically investigated. In addition, the close contact between animal and human populations may be a high risk factor for acquiring such bacteria.

$P$. aeruginosa produces two different ADPribosyltransferase toxins: exotoxin A (ETA) and exoenzyme $\mathrm{S}(4,5)$. The majority of $P$. aeruginosa strains produce the highly toxic ETA which inhibits eukaryotic protein biosynthesis at the level of polypeptide chain elongation factor 2 . The high percentage of tox $A$ gene ( $80 \%$ ) among the $P$. aeruginosa isolates may seriously threaten public health, as ETA is cytotoxic to numerous mammalian cells (17). Importantly, in our study all carbapenem-resistant $P$. aeruginosa isolates harboured tox $A$ gene.

To explain the possible genetic link between the activity of exotoxin A gene and antibiotic resistance inherited in $P$. aeruginosa, a phylogenetic tree was constructed based on the three tox $A$ sequences recovered from carbapenem-resistant $P$. aeruginosa isolates from cattle (KY407567), water (KY407566), and humans (KY454872) and aligned with the other related tox $A$ gene sequences obtained from GenBank (Fig. 1). Analysis of these sequences demonstrated that cattle and water isolates were found in the same cluster and are more related to each other than human isolates. This finding reflects the environmental origin of $P$. aeruginosa and highlights the potential role of contaminated water in the transmission of highly pathogenic CRPA to livestock and subsequently to humans. Epidemiologically, hospitals and healthcare settings are regarded as reservoirs for large numbers of pathogenic Pseudomonas strains. Wastewater from hospitals may contain a large number of these bacteria, some of which can also be multidrug resistant $(3,24)$. Therefore, we cannot eliminate the possibility of water contamination by hospital wastewater.

In conclusion, the presence and persistence of CRPA in non-human sources may pose a great risk to public health. Environmental water may play a pivotal role in transmission of CRPA between humans and animals and this requires further work to fully characterise and quantify the input of CRPA strains specifically from hospitals compared with those originating from the general community or other wastewater-related sources.

Conflict of Interests Statement: The authors declare that there is no conflict of interests regarding the publication of this article.

Financial Disclosure Statement: The authors declare that they did not have any funding source or grant to support their research work. The authors are committed to paying the publication fees with their own funds.

Ethics Statement: Ethical clearance to use human subjects was obtained from the designated health facility at Cairo University, Giza, Egypt. Written consent was obtained from each person upon provision of information on the intended use of those samples.

Animal Rights Statement: Collection of samples was conducted according to the guidelines of the Ethical Committee of the Faculty of Veterinary Medicine, Cairo University, Egypt.

\section{References}

1. Al-Daraghi W.A., Abdullah Z.H.: Detection of exotoxin A gene in Pseudomonas aeruginosa from clinical and environmental samples. J Al-Nahrain University 2013, 16, 167-172.

2. Barben J., Hafen G., Schmid J.: Pseudomonas aeruginosa in public swimming pools and bathroom water of patients with cystic fibrosis. J Cyst Fibr 2005, 4, 227-231. doi: 10.1016/ j.jcf.2005.06.003.

3. Beceiro A., Tomás M., Bou G.: Antimicrobial resistance and virulence: a successful or deleterious association in the bacterial world? Clin Microbiol Rev 2013, 26, 185-230. doi:10.1128/ CMR.00059-12.

4. Bever R.A., Iglewski B.H.: Molecular characterization and nucleotide sequence of the Pseudomonas aeruginosa elastase structural gene. J Bacteriol 1988, 170, 4309-4314.

5. Bodey G.P., Bolivar R., Fainstein V., Jadeja L.: Infections caused by Pseudomonas aeruginosa. Rev Infect Dis 1983, 5 , 279-313. http://dx.doi.org/10.1093/clinids/5.2.279.

6. Cholley P., Gbaguidi-Haore H., Bertrand X., Thouverez M., Plésiat P., Hocquet D., Talon D.: Molecular epidemiology of multidrug-resistant Pseudomonas aeruginosa in a French university hospital. J Hospital Infect 2010, 76, 316-329.

7. Clinical and Laboratory Standards Institute. Performance standards for antimicrobial susceptibility testing; twenty-fourth informational supplement. Document M100-S24. Wayne, CLSI. 2016.

8. Haenni M., Hocquet D., Ponsin C., Cholley P., Guyeux C., Madec J.Y., Bertrand X.: Population structure and antimicrobial susceptibility of Pseudomonas aeruginosa from animal infections in France. BMC Vet Res 2015, 11, 9.

9. Hamza E., Dorgham S.M., Hamza D.A.: Carbapenemaseproducing Klebsiella pneumoniae in broiler poultry farming in Egypt. J Global Antimicrobial Res 2016, 7, 8-10.

10. Hancock R.E.W., Brinkman F.S.: Function of Pseudomonas porins in uptake and efflux. Annu Rev Microbiol 2002, 56, 17-38.

11. Hikal W.M., Hakim A.S., Dorgham S.M.: Interaction of Acanthamoeba species with some pathogenic bacteria isolated from the same water sources. J Appl Sci Res 2013, 9, 3646-3658.

12. Khan N.H., Ishii Y., Kimata-Kino N., Esaki H., Nishino T., Nishimura M., Kogure K.: Isolation of Pseudomonas aeruginosa from open ocean and comparison with freshwater, clinical, and 
animal isolates. Microb Ecol 2007, 53, 173-186. doi: 10.1007/ s00248-006-9059-3.

13. Klockgether J., Cramer N., Wiehlmann L., Davenport C.F., Tummler B.: Pseudomonas aeruginosa genomic structure and diversity. Front Microbiol 2011, 2, 150.

14. Kümmerer K.: Resistance in the environment. J Antimicrob Chemother 2004, 54, 311-320.

15. Lee D.Y., Lauder H., Cruwys H., Falletta P., Beaudette L.A.: Development and application of an oligonucleotide microarray and real-time quantitative PCR for detection of wastewater bacterial pathogens. Sci Total Environ 2008, 398, 203-211. doi: 10.1016/j.scitotenv.2008.03.004.

16. Manenzhe R.I., Zar H.J., Nicol M.P., Kaba M.: The spread of carbapenemase-producing bacteria in Africa: a systematic review. J Antimicrob Chemother 2015, 70, 23-40.

17. Matthew P.: The role of exotoxin A in Pseudomonas disease and immunity. Rev Infect Dis 1983, 5, 979-984.

18. Ohnishi M., Sawada T., Hirose K., Sato R., Hayashimoto M., Hata E., Yonezawa C., Kato H.: Antimicrobial susceptibilities and bacteriological characteristics of bovine Pseudomonas aeruginosa and Serratia marcescens isolates from mastitis. Vet Microbiol 2011, 154, 202-207.

19. Oliver J.D.: The viable but nonculturable state in bacteria. J Microbiol 2005, 43, 93-100.

20. Quinn P.J., Carter M.E., Markey B.K., Carter G.R.: Enterobactereaceae. In: Clinical Veterinary Microbiology, Wolfe Publishing, London 1994, pp. 109-135.

21. Schwartz T., Volkmann H., Kirchen S., Kohnen W., Schön-Hölz K., Jansen B., Obst U.: Real-time PCR detection of Pseudomonas aeruginosa in clinical and municipal wastewater and genotyping of the ciprofloxacin-resistant isolates. FEMS Microbiol Ecol 2006, 57, 158-167.
22. Selezska K., Kazmierczak M., Müsken M., Garbe J., Schobert M., Häussler S., Wiehlmann L., Rohde C., Sikorski J.: Pseudomonas aeruginosa population structure revisited under environmental focus: impact of water quality and phage pressure. Environ. Microbiol 2012, 14, 1952-1967.

23. Silby M.W., Winstanley C., Godfrey S.A., Levy S.B., Jackson R.W.: Pseudomonas genomes: diverse and adaptable. FEMS Microbiol Rev 2011, 35, 652-680.

24. Streeter K., Katouli M.: Pseudomonas aeruginosa: a review of their pathogenesis and prevalence in clinical settings and the environment. Infect Epidemiol Med 2016, 2, 25-32.

25. Toval F., Guzmán-Marte A., Madriz V., Somogyi T., Rodríguez C., García F.: Predominance of carbapenem-resistant Pseudomonas aeruginosa isolates carrying blaIMP and blaVIM metallo- $\beta$-lactamases in a major hospital in Costa Rica. J Med Microbiol 2015, 64, 37-43.

26. Walsh T.R., Payne D.J., MacGowan A.P.: Bennett P.M.: A clinical isolate of Aeromonas sobria with three chromosomally mediated inducible $\beta$-lactamases: a cephalosporinase, a penicillinase, and a third enzyme, displaying carbapenemase activity. J Antimicrob Chemother 1995, 35, 271-279.

27. World Organization for Animal Health (OIE): OIE list of antimicrobial agents of veterinary medicine 2015. http://www.oie.int/fileadmin/Home/eng/Our scientific expertise/docs/ pdf/Eng_OIE_List_antimicrobials_May (2015).pdf.

28. Xu J., Moore J.E., Murphy P.G., Millar B.C., Elborn J.S.: Early detection of Pseudomonas aeruginosa - comparison of conventional versus molecular (PCR) detection directly from adult patients with cystic fibrosis (CF). Ann Clin Microbiol Antimicrobiol 2004, 3, 21. 